\section{Fashion film: tendencia mundial en comunicación}

Pablo Andrés Tesoriere *

Resumen: Año a año, se multiplican las visualizaciones de los fashion films en YouTube y Vimeo. Es deber obligatorio para las grandes marcas contratar realizadores cinematográficos de renombre para generar piezas audiovisuales que logren captar el estilo de vida de la marcay puedan lograr acaparar la mayor cantidad de público posible, sin perder sofisticación y elitismo. Pero ¿qué es realmente un fashion film? y ¿cuáles son los límites de este nuevo lenguaje?. Lo cierto es que hablamos de un producto que se encuentra entre lo cinematográfico y lo publicitario, bordeando los límites del videoarte y lo editorial.

Palabras clave: fashion film - storytelling - cine - identidad - moda - branded content comunicación - postproducción - narrativa audiovisual.

[Resúmenes en inglés y portugués en la página 240]

${ }^{(*)}$ Director de Cine, Universidad del Cine.Fundador de la Productora Audiovisual Bagual. Profesor de la Universidad de Palermo, facultad de Diseño y Comunicación.

Un nuevo género es siempre la transformación de uno o varios géneros antiguos: por invención, por desplazamiento, por combinación.

(Todorov, 2012, p. 34)

"La revolución digital ha transformado la totalidad de medios, formatos y soportes del sector comunicativo tradicional sin distinción alguna, promoviendo la aparición de nuevos contenidos y de nuevas formas de contar historias" (Jódar Marín, 2019, p. 137). Con el paso del tiempo, las marcas se van aggiornando, dejando de lado los formatos obsoletos de la industria, para publicitarse en redes sociales como Instagram, Facebook y canales como YouTube y Vimeo, mediante la realización de fashion films, constituyéndose en un formato audiovisual innovador. Por otro lado, las mismas marcas modifican sus sitios web, para darles prioridad a sus videos propios.

La publicidad tiene como objetivo principal llegar al público buscando atención e interés a través de mensajes centrados en un producto. Los cambios impuestos por la era digital 
generaron grandes cambios en el mundo publicitario, estableciendo como eje prioritario para las marcas, la conexión con el consumidor, desde lo emocional. "El consumidor, ha pasado de ser un simple receptor pasivo a ser un actor activo en el proceso de marketing: Un prosumidor, que participa de la comunicación" (Costa-Sánchez, 2014, p. 4).

Se habla de la crisis de la publicidad tradicional, debido a los cambios que en las últimas décadas han comportado la sociedad del conocimiento, las hipermediaciones de la teoría de la comunicación digital interactiva y el paso del paradigma de la transmisión al de la participación en el diálogo postmoderno de las audiencias (Castelló y Del Pino, 2014, p. 169).

El consumidor es un ser crítico y exigente con las marcas, generando, como consecuencia, que éstas recurran a nuevos formatos para promocionarse, evolucionando y reinventándose. El contenido del anuncio no tiene como único fin la venta del producto, sino el vínculo de la marca con el consumidor.

Hasta hace algún tiempo la publicidad ha perseguido como objetivo principal alcanzar a su público/ meta, buscando su atención y su interés a través de mensajes repetitivos centrados en el producto. Las condiciones del escenario actual han hecho que esta situación cambie (Castelló y Del Pino, 2014, p. 171).

Las marcas continúan sorteando los límites, y el siguiente paso de la escalada ha sido convertirse en los propios proveedores del entretenimiento. Ya sea en forma de videojuego (advergaming) o en cualquier otro formato de ocio (advertainment), las firmas comienzan a producir sus propios contenidos impregnados del universo de marca, con el fin de integrar su mensaje y sus valores en anuncios que el público está dispuesto e interesado en ver, disfrutar y compartir (Macías Muñoz, 2014, p. 5).

A partir de este paradigma digital, surgen los fashion films en la industria de la moda, articulando un lenguaje propio sustentado de innovación audiovisual y post-producción digital, apostando por lo emocional y acercándose al estilo de la vida del consumidor.

En efecto, de un tiempo a esta parte, las marcas de moda ya han constatado que sus tiendas no son tan visitadas como antes, y que se han vuelto simples lugares de exhibición más que centros de compra; asimismo, las revistas de moda, que hasta hace poco eran el referente para encontrar tendencias, hoy, debido a la inmediatez de internet y el aumento de poder del consumidor, han quedado como referencias de segundo orden (Díaz, 2016, p. 46).

Los fashion films son cortometrajes que rondan los límites de lo cinematográfico, lo publicitario, el videoarte, el videoclip y lo editorial. Les dan prestigio a las marcas, compiten en festivales de cine, de publicidad y desde ya hace un tiempo y en todo el mundo, hay festivales creados exclusivamente para ellos mismos. Según José Murciano, director de Fashion Film Madrid, los ingredientes imprescindibles de un buen fashion film, son: una estética muy cuidada, una buena historia y la generación de sensaciones y sentimientos en el espectador. Es un formato emergente vinculado directamente con la comunicación en moda, dejando de lado la publicidad tradicional audiovisual y las publicaciones en papel (revistas de moda).

Las editoriales de moda se enfrentaron a una metamorfosis en los medios, en los formatos y en los soportes de comunicación ante el avance tecnológico en la era de los nativos 
digitales. Internet es la protagonista principal en esta era de comunicación audiovisual. "Los medios de los que disponemos nos permiten establecer y proyectar espacios para crear y ofertar nuevos contenidos en un lugar propio. Lo que posibilita, además, ofertas personalizadas para una audiencia personalizada" (Caerols y De la Horra, 2015, p. 339).

El fashion film es un género versátil, innovador y novedoso. Irrumpe como respuesta a una demanda de los medios y del consumidor, como una nueva forma de establecer la imagen de la moda y los valores de las marcas, estableciendo un modelo de comunicación que va más allá del simple discurso.

Trabajos como los de Paloma Díaz y Leticia García culminan con la identificación de las siguientes cinco características definitorias de los fashion films en el marco del marketing editorial y la comunicación en moda: 1) su conexión muy estrecha con el engagement, 2) el establecimiento de nuevas formas de interactividad con los nuevos consumidores digitales, 3) la búsqueda del deleite estético, 4) la articulación discursiva basada en el storytelling y la serialización y por último 5) la desmaterialización de los productos alejándolos del mero diseño de producto físico y presentándolos como piezas con vida propia y personalidad en puestas en escena cargadas de expresividad (Jódar Marín, 2019, p. 137).

A través de los fashion films las marcas de moda buscan interactuar con sus consumidores invitándolos a participar de su universo de marca a través de relatos impregnados de valores que conectan con sus emociones. Relatos cuidadosamente realizados que combinan arte, moda, música, cine y publicidad y logran con ello un engagement con el público, destacando la belleza y estética de la pieza audiovisual (Del Pino y Castelló, 2015, p. 107). La duración de un cortometraje de moda va desde los treinta segundos hasta los doce minutos, dependiendo del formato (soportes digitales) hacia donde va dirigido. Muchas veces las marcas establecen tres versiones del mismo cortometraje, según el medio. En ocasiones, los límites son estéticos de las propias marcas, por otro lado, las redes digitales imponen sus propios límites. Un video para Instagram puede durar como máximo un minuto mientras que la misma historia puede tener una versión de siete minutos para enviar a festivales de cine, presentación de colecciones o en la semana de la moda.

El fashion film presenta un discurso audiovisual capaz de articular nuevos contenidos para plasmar la imagen de la moda, basándose en una experiencia seductora en torno a tres minutos de duración, y donde la articulación del lenguaje audiovisual resulta clave para la consecución de sus objetivos. La brevedad en la duración de estas piezas audiovisuales resulta un elemento clave, justificado en las estrategias de marketing online además del diseño propio de una obra artística concebida para el deleite estético y su distribución en plataformas digitales y redes sociales (Jódar Martin, 2019, p. 148).

Desde el nacimiento del arte audiovisual, el cine y la moda han tenido una relación cercana, y han evolucionado en los últimos tiempos, hacia el fashion film, como un género nuevo, con sus propias reglas, estableciendo una manera de informar caracterizada por técnicas narrativas que van desde el cine clásico, pasando por el videodanza, hasta el cine experimental de las vanguardias del surrealismo. El cine se pone al servicio de la moda, y en él, las marcas contratan a directores importantes como Martin Scorsese, Sofía Coppola, Spike Jonze, David Lynch, David Fincher, entre otros, para hacer sus cortometrajes de moda. En Argentina, se destacan la directora de cine Lucrecia Martel y el fotógrafo de moda Gabriel Rocca. 
"La identidad de una marca es el conjunto de valores tangibles o intangibles que hacen a una marca distinta de la otra" (Torregrosa, 2015, p. 176). La publicidad tradicional en el medio más convencional (la televisión) es cada vez menos eficiente, logrando una conexión nula con el consumidor, sobre todo en los más jóvenes. Es un nuevo escenario donde el marketing de las marcas está directamente relacionado con la identificación que logre sentir el consumidor.

Las redes sociales han conseguido compaginar la utilidad para el consumidor, con la capacidad que tienen para generar ingresos, presentes y futuros, a través de la información aportada por el consumidor y los anuncios (personalizados) que se les hacen llegar a los miembros delas redes sociales. Las redes sociales están llamadas a convertirse en la mejor herramienta de marketing posible, utilizando a los contactos de los usuarios como mensajeros. Así, se sitúan en un lugar privilegiado para que los mensajes publicitarios sean oídos y se les otorgue confianza (Gangadharbatla, 2008, p. 11).

Es una era de revolución digital donde el fashion film se potencia como una nueva manera de comunicación de las marcas, en donde se destaca la estética y belleza del mensaje mediante estrategias de branded content y marketing. "Este nuevo escenario ha obligado a las marcas a generar un engagement que vaya más allá de la transacción comercial y buscar nuevos formatos y herramientas que porten contenido e interés para el público" (Del Pino y Castelló, 2015, p. 124).

Se deja de lado la venta de productos concretos como en la publicidad pura, y se da rienda a la historia y la identidad de la marca, utilizando los recursos del storytelling y lenguaje audiovisual, en la búsqueda el deleite estético y presentando los productos como piezas de la vida propia. Desde el punto de vista industrial, Paloma Díaz Soloaga entiende el Fashion Film como un vehículo de comunicación que construye marcas en la era digital.

A través del storytelling, el fashion film promueve más valores e historias que productos y argumentos. Las marcas de moda se vuelcan a una comunicación emocional y narrativa, que apuesta por la originalidad y autenticidad, logrando ser eje de entretenimiento frente a un espectador más exigente. "Con este nuevo enfoque, el contenido del anuncio está al servicio de la marca y no tiene como único fin la venta del producto, sino la vinculación marca-consumidor" (García y Rodríguez, 2018, p. 10).

"Las películas de moda se consideran principalmente como una herramienta de marketing experimental de firmas de moda de lujo que utilizan la narración y la estética fílmica para promover marcas y establecer relaciones de consumo más cercanas e íntimas" (Díaz Soloaga, 2012 p. 3). A partir de los fashion films, surge el branded content, donde el producto es el contenido en sí mismo. Las marcas generan su contenido compartiéndolo con los usuarios, pretendiendo relacionarse y compartir, y no tanto vender.

Una fusión de publicidad y entretenimiento en un mismo producto de comunicación al servicio del marketing que se integra en la estrategia global de marca de una organización y que está destinada a ser distribuida como contenido de entretenimiento con un elevado nivel de calidad (Horrigan, 2009, p.51).

Distanciándose de la publicidad tradicional, el branded content se centra en elementos narrativos y no persuasivos, y establece así una manera distinta de presentación de la marca, que busca la fidelidad del consumidor. "El consumidor busca a la marca, se interesa por lo que ésta tiene que ofrecerle, y, para ello, lo único que ha tenido que hacer el anunciante 
es brindarle un contenido que realmente le interese: entretenimiento" (Macías Muñoz, 2014, p. 5).

"Este formato más que persuadir pretende generar interés, aporta contenido que los usuarios quieren conocer" (Costa-Sánchez,2014, p. 85). El branded content trabaja con los gustos, intereses y estilo de vida de los consumidores, a través del storytelling, buscando viralidad, por medio de las redes sociales. Los consumidores comparten con sus allegados el contenido. En una época marcada por la revolución digital, el branded content logra adaptarse a diferentes soportes audiovisuales y digitales, eventos (desfiles de moda, festivales de cine), juegos (aplicaciones de celulares) y música (conciertos, videoclips).

La innovación se produce en las estrategias de comunicación y en los canales de transmisión. Los nativos digitales nacieron con la internet como un medio eficaz de opinión, información, debate y formando parte de estrategias de marketing. Las marcas, encontraron en el fashion film, la herramienta ideal para acercarse a los nativos digitales. instagram y facebook tienen en común una naturaleza interactiva, y ambas son herramientas con un alto potencial persuasivo. "El rol del consumidor en la comunicación comercial ha cambiado. De ser sujeto pasivo, un mero receptor de la comunicación, pasa a tener un rol activo, buscar la comunicación, participar en ella, vivirla, expandirla e incluso realimentarla" (García, 2007, p. 83).

Las marcas, al compartir información audiovisual, no sólo generan tendencia y se imponen en el mercado, sino también consiguen que los usuarios que las siguen, se sientan inmersos en la creación de la identidad de ellas mismas y partícipes de los universos imaginarios que proponen, mediante los recursos cinematográficos. Hay un concepto que engloba todo este fenómeno: el de ser exclusivo sin ser excluyente. Es un producto más sensorial que persuasivo, que apela a las emociones.

"Asimismo, las redes sociales han logrado unir comunidades sin importar la distancia geográfica, impulsando la creación rápida de prototipos culturales, surgiendo nuevos talentos y nuevos géneros de contenido"(Holt, 2016, p. 9). El fashion film rompe el límite entre el consumo y la representación, basándose en un lenguaje puramente cinematográfico, jugando con lo experimental, utilizando medios visuales para llegar a una nueva audiencia de clientes potenciales que son los nativos digitales.

José Murciano, en una entrevista en el 2015, habla de:

Conectar con el público, transmitir una serie de valores, eso es lo que busca un fashion film. No nos interesa vender un producto, ni ofrecer un servicio, nos interesa crear un mundo imaginario en el que el espectador respire el universo de la marca.

El cine, con sus mundos imaginarios, es el medio que mayor empatía genera en el espectador: identifica con sus héroes o heroínas, imita su manera de vestir, averigua las marcas que visten a las estrellas, y adopta identidades. Es a través de estrategias como el fashion film donde se genera el deseo de pertenencia a la marca.

El código cinematográfico no debe entenderse como un conjunto de reglas rígidamente estructuradas que deciden la relación entre significante y significado, sino como un ámbito en el que se establecen una serie de conexiones lógicas que hacen posible que un 
mensaje sea comprendido. El realizador pone en funcionamiento una innumerable cantidad de configuraciones significantes o códigos para que su materia de la expresión hable al espectador (Mirzoeff, 2003, p. 186).

El fashion film no siempre implica descaradamente al espectador como consumidor $y$, en general, tiene un mayor grado de autonomía con respecto a las modas que exhibe o connota, ya que está menos preocupado por los aspectos sociales y psicológicos de la identificación, la persuasión y la tranquilidad de lo que es. Caso en la publicidad más convencional (Uhlirova, 2013, p. 150).

La finalidad de un fashion film no es la venta de un producto sino la argumentación persuasiva. Se busca seducir mediante las emociones y los sentimientos y no convencer con argumentos racionales como la publicidad propia de la televisión. Hay un propósito comercial, pero debe quedar escondido a través de las herramientas del lenguaje audiovisual del cine: puesta en escena y relato. Esto hace que la duración de los mismos sea superior a la de los comerciales y se asemejen a los cortometrajes cinematográficos.

El branding, entendido como proceso de creación y gestión de la marca como activo de valor ha relevado a la comunicación publicitaria convencional. Ya no se trata tanto de argumentar las virtudes de un producto como de comunicar los valores de la marca que lo avala... El e-commerce, cada vez más pujante, o la proliferación de marcas de menor gama con productos similares han que este mercado tenga que replantearse sus modos de comunicar (Díaz Soloaga, 2012, p. 3).

El storytelling no se centra en contar historias, sino en llevarlo a cabo de una manera en que el mensaje cobre fuerza y conexión con el consumidor, y tiene como objetivo principal, atraer y crear deseo, por medio de valores emocionales.

El storytelling, a través de sofisticadas herramientas como los productos de branded content, no pretende persuadir a la audiencia sobre las bondades de un producto, sino conectar con el componente emocional de los usuarios generando un vínculo afectivo de apego que garantice la lealtad hacia la marca (Tur y Segarra, 2014, p. 120).

El consumidor que ve un fashion film, no lo considera invasivo, como la publicidad tradicional. Es contar una historia de manera creativa, donde la marca actúa como narrador de una historia.

El concepto de storytelling es tan antiguo como la publicidad, pero su uso para la construcción y difusión de identidad de marca es una tendencia reciente que ha crecido al amparo del branded content, pues éste ha creado la posibilidad de contar historias de marca de forma más sutil, más emotiva y más proclive a generar verdadera conexión con el público (Méndiz Noguero, 2018, p. 319).

Con el tiempo, los valores de identidad del ser humano van cambiando. No sólo el espectador se reconoce en el héroe o la heroína. Por el contrario, ganaron popularidad los villanos, el aventurero, las y los seductores, y los raros y diferentes les disputan terreno en el mundo de la moda, a la belleza perfecta. Valores como el idealismo, la libertad, la lucha de clases, el empoderamiento de la mujer, las minorías o la rebeldía, son explotados por las marcas para buscar conectarse con el consumidor. Los fashion film se nutren de estos 
cambios para generar sus relatos logrando conectar la identidad de la marca con los valores de la sociedad, en un mundo donde todo es posible.

Las historias funcionan porque queremos experimentar emociones, sentimientos y pasiones de otros que se han topado con los retos a los que nos enfrentamos a diario. Nos encanta ver a un héroe prevalecer, a los malos recibir su merecido, o llorar con una trágica pérdida (Cooke, 2008, p. 36).

Hay siete tipos de fashion film: A) Películas donde se impone el producto, que a diferencia de los comerciales, no impulsan la venta. B) "Día en la vida", de tipo documental, que por lo general cuentan como protagonista con un influencer de las redes digitales, y logran conectarse con los consumidores e interactúan con la identidad de las marcas. C) Películas narrativas, con un guion cinematográfico, donde hay una introducción, nudo y desenlace y se nutren de los géneros cinematográficos. Se contratan para su realización directores de cine reconocidos y estrellas de la actuación consagradas. D) Musical, donde el montaje de las imágenes está minuciosamente construido a partir del ritmo de la banda sonora. E) Películas de modo experimental, donde no hay una narración clásica y se nutren de las vanguardias, el videoarte y el videodanza, logrando videos de tiempos largos, ricos visualmente. Sin embargo, corren el riesgo de ser para un público muy particular y no lograr conexión con la mayoría de los consumidores. F) Documental, donde generalmente se muestran las confecciones de las prendas y se editan atractivamente tomas de texturas de los tejidos con entrevistas a los propios diseñadores. G) Lookbook, conviven con el catálogo fotográfico de la marca, generando un video atractivo con movimientos en estudio, con todas las prendas que se lanzarán en la temporada.

Podemos encontrar rastros de varios géneros en juego dentro de los individuales. Es común que un fashion film entre en varios de los tipos de fashion film. Es usual que un género crezca, se inspire o interactúe con otros, y hasta con otras artes. Es común encontrar en los fashion films restos del videoclip, en cuanto al uso musical, restos del cine arte, en cuanto al predominio de la cámara lenta y los fuera de foco y restos del cine clásico policial de Hollywood, en cuanto a criterios de narración y construcción de personajes. Sin embargo, los fashion films no son del todo comerciales, tampoco completamente documentales, y tampoco son del todo abstractos o completamente narrativos. Se puede decir que son un "híbrido" de todos los géneros y esa es su característica principal y funcionan con un doble objetivo: promocionar productos desde un lado más sensorial y comunicar la identidad de la marca.

Consideramos, sin embargo, que narración y videoarte no son dos tendencias contrapuestas en el mundo del fashion film, sino los dos extremos de las múltiples formas en las que que éstos pueden plasmarse. Si esta nueva estrategia de comunicación de marca es tan efectiva y exitosa es porque permite aglutinar el universo y los principios de cada una de ellas (Díaz Soloaga, 2012, p. 11).

Está comprobado que la publicidad invasiva tradicional ha dejado de funcionar. Los consumidores no se limitan a ver un anuncio, sino que buscan participar activamente y se involucran con las marcas. Por otro lado, éstas han tenido que evolucionar en los valores de identidad que transmiten, para lograr la conexión deseada.

El fashion film es fruto de las nuevas oportunidades que ofrece Internet respondiendo a las necesidades de un público nuevo que demanda contenidos nuevos, quedando mani- 
fiesto el proceso de adaptación de las marcas de moda al nuevo ecosistema comunicativo (Jódar Marín, 2019, p. 18).

Las marcas de moda centralizan sus estrategias de comunicación hacia la Internet y las redes sociales, promocionan productos y comunican identidades a través del lenguaje cinematográfico, seleccionan actores y/o actrices famosos y directores de cine prestigiosos a nivel mundial. El objetivo principal del fashion film es transmitir un estilo de vida, abren un mundo de fantasías que nos permite mirar el nuestro, y seducen a través de las emociones, sin convencer con argumentos racionales.

Gracias al avance de la tecnología y la aparición de las redes sociales, la publicidad tiene un nuevo canal para explotar; las redes sociales juegan un papel importante en la difusión y viralidad de los contenidos de marca. Asimismo obligan a las mismas a crear un contenido de calidad, relevante que realmente llame la atención del prosumidor, debido a este es un entorno en el que el usuario suele prestar atención de manera breve a los contenidos y tiene la libertad y facilidad de pasar a otro contenido que realmente le satisfaga (García y Rodríguez, 2018, p. 9).

El branded content y el storytelling son dos conceptos conectados directamente con la realización de los fashion films, y generan historias para narrar y medios a través de los cuales poder contarlas. Constituyen un modo de generar discurso a través de la construcción de relatos, mostrando los valores de una marca.

Al fusionar cine, música, moda, arte y publicidad, los fashion films permiten llegar a un público muy amplio que no sólo está interesado en la moda, sino también en el arte, la fotografía y la música. Logran integrar los valores de las marcas y publicitan el producto de una manera sutil, ofreciendo un contenido de calidad, no invasivo.

\section{Lista de Referencias Bibliográficas}

Bozal, V. (1999). Historias de las ideas estéticas y de las teorías estéticas contemporáneas II. Madrid: Editorial Visor.

Butchart, A. (2016). The Fashion of film How Cinema has inspired fashion. Inglaterra: Orion. Caerols, M. R. y De La Horra Veldman, Y. (2015). Fórmulas creativas en la publicidad de moda. Un análisis de Madrid Fashion Film Festival y su impacto en las redes sociales. Recuperado de: http://www.redalyc.org/pdf/3537/353744530011.pdf

Casu, I. (2018). Fashion Film: an historical framework. España: Recuperado de: https://www. academia.edu/38235609/Fashion_Film_An_Historical_Framework

Castelló, A. y Del Pino, C. (2014). Conectando con el público joven a través de los contenidos: el caso Coca-Cola. Recuperado de: https://dialnet.unirioja.es/servlet/libro?codigo $=557544$

Costa-Sánchez, C. (2014). El cambio que se viene. Audiovisual branded content. España: Telos. Recuperado de: https://www.researchgate.net/publication/299777031_El_cambio _que_viene_Branded_content_audiovisual

Costa-Sánchez, C. (2014). Transmedia Storytelling, an ally of Corporate Communication: Dropped by Heineken case study. Communication and Society. España: Universidad de Na- 
varra. Recuperado de: https://www.researchgate.net/publication/288646254_Transmedia _storytelling_an_ally_of_corporate_communication_dropped_by_heineken_case_study

Del Pino, C. y Castelló, A. (2014). Análisis del Branded Content en televisión: estudio de casos españoles. España: Revista de Comunicación de la SEECI. Recuperado de: http://www. seeci.net/revista/index.php/seeci/article/view/74

Del Pino, C. y Olivares, F. (2006). Brand placement: integración de marcas en la ficción audiovisual. España: Gedisa.

Díaz Gandasegui, V. (2011). Mitos y realidades de las redes sociales. Información y comunicación en la sociedad de la información. España: Prisma social. Recuperado de: https://dialnet. unirioja.es/servlet/articulo?codigo $=3686439$

Di Paolo, A. (2015). Fashion Film. A new media aesthetics in the digital era. Italia: ZoneModa Journal 5. Recuperado de: https://www.academia.edu/25918087/Fashion_Film._A_new_ media_aestethic_inthe_digital_era

García, S y Rodríguez, F. (2018). Comunicación publicitaria en la industria de la moda: branded content, el caso de los fashion films. Recuperado de: http://www.scielo.org.pe/ $\mathrm{pdf} / \mathrm{rcudep} / \mathrm{v} 17 \mathrm{n} 1 / \mathrm{a} 02 \mathrm{v} 17 \mathrm{n} 1 . \mathrm{pdf}$

Holt, D., Arrese, A. y Pérez-Latre, F.J. (2016). Branding in the age of social media. Estados Unidos: Harvard Business Review. Recuperado de: https://hbr.org/2016/03/brandingin-the-age-of-social-media

Horrigan, D. (2009). Branded content: a new model for driving Tourism via film and branding strategies. Munich: Munich Personal RePEc Archive. Recuperado de: https://mpra. ub.uni-muenchen.de/25419/

Jódar-Marín, J. A. (2019). La puesta en escena y la postproducción digital del Fashion Film en España.. El nuevo formato audiovisual de comunicación en moda concebido para Internet. España: RAEIC. Recuperado de: http://www.revistaeic.eu/index.php/raeic/article/ view/192

Gangadharbatla, H. (2008). Facebook me: Collective self-esteem, need to belong and Internet self-efficacy as predictors of the ingeneration's attitudes toward social networking sites. Estados Unidos: Journal of Interactive Advertising. Recuperado de: https://www.scirp.org/(S(czeh2tfqyw2orz553k1w0r45))/reference/ReferencesPapers. aspx?ReferenceID $=2312962$

Landis, D N. (2003). Diseño de Vestuario: cine. Barcelona: Blume.

Kapferer, J N. (1992). La marca, capital de la empresa. España: Deusto.

Macías Muñoz, G. (2014). La integración de los valores de marca en los fashion films a través del guión: el caso Lady Dior. Recuperado de: https://idus.us.es/xmlui/handle/11441/25482

Méndiz Noguero, A. (2018). Valores y storytelling en los fashion films. El caso Tender Stories de Tous. España: Revista de comunicación 17. Recuperado de: http://www.scielo.org.pe/ pdf/rcudep/v17n2/a15v17n2.pdf

Mirzoeff, N. (2003). Una introducción a la cultura visual. Barcelona: Paidós Ibérica S.A.

Noguera, M y Torregrosa, M. (2015). Los fashion films como relatos audiovisuales de marca. España: Sádaba

Rees-Roberts, N. (2019). Fashion Film: Art and Advertising in the Digital Age. Inglaterra: Berg Publishers.

Saulquin, S. (2010). La muerte de la moda, el día después. Buenos Aires: Editorial Paidós. 
Soloaga Díaz, P. (2012). Fashion Films: nuevas tendencias en la comunicación de marca. Madrid: Universidad Complutense de Madrid. Recuperado de: http://gfc-conference. eu/files_download/GFC2012/DIAZ\%20SOLOAGA\%20and\%20GUERRRERO\%20 -\%20Fashion\%20Films_Nuevas\%20tendencias\%20en\%20la\%20comunicacion\%20 de\%20marca.pdf

Todorov, T (2012). Teoría de los géneros. Argentina: Waldhuter.

Tur, V. y Segarra, J. (2014). «Branded Content» $y$ «Storytelling». El arte de crear contenidos y contar historias. Bajo la influencia del branded content: efectos de los contenidos de marca en niños y jóvenes. Madrid: ESIC. Recuperado de: https://dialnet.unirioja.es/servlet/ articulo? codigo $=4687700$

Wille, J. (2019). Understanding Fashion Film, Form and Genre. Inglaterra: Kosmorama. Uhrilova, M. (2013). 100 Years ofthe Fashion Film: Frameworks and Histories. Inglaterra: Fashion Theory Journal. Recuperado de: https://www.academia.edu/7357227/100_Years_ of_the_Fashion_Film_Frameworks_and_Histories

\begin{abstract}
Year by year, the visualizations of fashion films on YouTube and Vimeo are multiplied. It is mandatory for large brands to hire renowned filmmakers to generate audiovisual pieces that capture the lifestyle of the brand and can manage to capture as many audiences as possible, without losing sophistication and elitism. But what is really a fashion film? And what are the limits of this new language? The truth is that we talk about a product that is between the cinematographic and the advertising, bordering the limits of video art and publishing.
\end{abstract}

Keywords: fashion film - storytelling - cinema - identity - fashion - branded content communication - postproduction - audiovisual narrative.

Resumo: Ano após ano, as visualizações de filmes de moda no YouTube e no Vimeo são multiplicadas. É obrigatório que grandes marcas contratem cineastas renomados para gerar peças audiovisuais que capturem o estilo de vida da marca e possam capturar o maior número possível de públicos, sem perder sofisticação e elitismo. Mas o que é realmente um filme de moda? E quais são os limites desse novo idioma? A verdade é que falamos de um produto que fica entre cinematográfico e publicidade, fazendo fronteira com os limites da videoarte e da publicação.

Palavras chave: filme de moda - narrativa - cinema - identidade - moda - conteúdo de marca - comunicação - pós-produção - narrativa audiovisual.

[Las traducciones de los abstracts fueron supervisadas por el autor de cada artículo] 